\title{
Comparative study of goal contents and goal characteristics between medical and business students
}

\author{
Soowon Park ${ }^{1,2}$, Ji Eun Kim ${ }^{3}$, Jun-Young Lee ${ }^{2}$ and Jongho Shin ${ }^{1}$ \\ ${ }^{1}$ Center for Learning Science \& Creative Talent Development, Department of Education, Seoul National University, \\ ${ }^{2}$ Department of Psychiatry, SMG-SNU Boramae Medical Center, Seoul National University, and ${ }^{3}$ Department \\ of English and English Literature, Department of Psychology, Korea University, Seoul, Korea
}

Purpose: Medical and business are one of the most popular majors among students, and both fields require intensive training to reach certain level of expertise. During the development of professionalism, goal can become a crucial role in psychological impetus. The purpose of this study is to compare goal contents, goal characteristics, and effect of goal characteristics on student's major satisfaction between medical and business.

Methods: A total of 193 undergraduate students (97 medical students, 96 business students) answered survey questions including goal contents, goal characteristics (goal autonomy, goal attainability, social value of goal) and satisfaction on their majors. Qualitative analysis of goal contents and quantitative analysis of goal characteristics, and their effects on student major satisfaction were performed.

Results: Goal content analysis showed percentage of social concern goal was higher in medical students $(25.8 \%)$ than business students $(6.3 \%)$, whereas percentage of wealth goal was higher business students $(24.0 \%)$ than medical students $(3.1 \%)$. Among goal characteristics, goal attainability and social value of goal were higher in medical students than business students. In both groups, social value of goal was significantly predict major satisfaction.

Conclusion: Goal contents and goal characteristics are different between medical and business students. Curriculum and educational interventions that concerning students' goal and developing programs to enhance students' social value of goal is necessary.

Key Words: Goal contents, Goal characteristic, Major satisfaction

\section{Introduction}

Goal is a critical psychological impetus of the continual development of professionalism in a field [1]. Goal setting heightens the internal motive for task performances, centralizes attention unto deeper immersion of the task, and finally has a positive effect in a behavioral dimension such as determining task strategies and retaining them [2]. It also acts as an important element that determines situational satisfaction, defined as an internal representation of desiring affairs, results and processes [3]. Therefore, in order to develop a student into a professional in one's field, a thorough examination of his/her goal is crucial.

Reflecting such importance, goal research is being carried out in education field, but most of which consists of achievement goal orientation related studies $[4,5]$. In
Received: November 2, 2015 • Revised: December 17, 2015 • Accepted: December 18, 2015 Corresponding Author: Jongho Shin (http://orcid.org/0000-0003-1154-2211)

Center for Learning Science \& Creative Talent Development, Department of Education, Seoul National University, 1 Gwanak-ro, Gwanak-gu, Seoul 08826, Korea Tel: +82.2.880.7640 Fax: +82.2.878.1665 email: jshin21@snu.ac.kr
Korean J Med Educ 2016 Mar; 28(1): 17-24.

http://dx.doi.org/10.3946/kjme.2016.5

eISSN: 2005-7288

(C) The Korean Society of Medical Education. All rights reserved. This is an open-access article distributed under the terms of the Creative Commons Attribution Non-Commercial License (http:// creativecommons.org/licenses/by-nc/3.0/), which permits unrestricted non-commercial use, distribution, and reproduction in any medium, provided the original work is properly cited. 
medical fields, which require an especially high standard of professionalism, identification of goal contents and goal characteristics are fundamental to understand students' motivation and develop curriculums. However, they remain largely unacknowledged. Therefore, this study examined upon medical students' goal contents and three goal characteristics - goal autonomy, goal attainability, social concerns of goal-and their relationship with major satisfaction, on the basis of goal content theory (GCT) [6].

GCT categorized goal contents into two main dimensions of intrinsic goal and extrinsic goal. Intrinsic goal refers to internally oriented goals such as selfgrowing goal, relational goal, help-seeking goal or health [7]. On the other hand, extrinsic goal refers to externally oriented goals such as economic success, social recognition or appearance. An individual who pursues intrinsic goal gains higher satisfaction and motivation level, through the fulfillment of three primary needs of autonomy, competence, and relatedness [8]. In connection with goal characteristics, autonomy equals the goal autonomy of decision-making, competence matches goal attainability, and relatedness is in regard to social value of goal.

This study compared medical students' goal contents and goal characteristics with business students. Medical and business majors require high admission grade and tuition, and these are one of the most popular majors among students. When considering the goal contents matter, the business major's wealth-oriented nature has given weight to its image as a representative major of extrinsic goal pursuit. As it has been disclosed in experiments of Kasser \& Ahuvia [9] or Vansteenkiste et al. [10], business students tend to show a lower level of well-being. For that reason, if medical students show more of extrinsic goal contents or lower-level goal characteristics, it signifies an urgent call for educational intervention.

Identifying the goal contents of medical students precisely is of significance in terms of human resource management and medical education. The reality that one has to face in the course of medical college life may deteriorate major satisfaction, supposing the situational orientation takes a different turn from one's ideal. Thus the verification experimental design of medical students' goal characteristics and their relationship with major satisfaction can be exploited as a basic data for medical college educational program. Research question of this study is as follows:

(1) What are the goal contents of medical students and business students?

(2) What are the goal characteristics (goal autonomy, goal attainability, social value of goal) of medical students and business students?

(3) What are the effects of medical students' and business students' goal characteristics on their major satisfaction?

\section{Subjects and methods}

\section{Participants}

Participants of this study were 193 undergraduate students (97 medical students, 96 business students) are recruited from two universities in Seoul and Suwon, South Korea. The mean age of medical students was 19.60 (standard deviation [SD], 2.78), consisting of 68 males (70\%) and 29 females (12\%). The mean age of business students was 20.57 (SD, 2.26), consisting of 61 males (64\%) and 35 females (36\%).

\section{Measures}

The survey questionnaire is comprised of three main 
parts. Demographics (i.e., major, age, gender) and satisfaction of major was measured in the first section. Major satisfaction was measured through a single question of "Are you satisfied with your current major?" The second section asked participants to write down their goals (i.e., "What is your life goal?") and reasons or events that affected setting his or her goal (i.e., "Please write the reasons or critical events that have an influence on setting a goal you wrote"). The third part consisted of items about goal characteristics (i.e., goal autonomy, goal attainability, social value of goal) of one's own life goal that was written in the first part. For all measures, a 5-point Likert-type scale was used (1=not at all, 3= neutral, 5=extremely).

\section{1) Goal autonomy}

Five items adopted from the scale of goal autonomy in the Goal Questionnaire for Engineering Experts [11] were used to measure students' goal autonomy. The original items were developed for engineering experts (e.g., I determined my engineering goal by myself) so the items were revised to eliminate the content of engineering. The revised items asked to indicate how participants set and pursue their own goals by themselves. Specific examples of items were "I determined my goal by myself," and "I chose my life goal because I hope to achieve it." The measurement showed high internal consistency (Cronbach $\alpha, 0.88$ ).

\section{2) Goal attainability}

Participants' goal attainability was assessed by five items that were adopted from the scale of goal attainability in Goal Questionnaire for Engineering Experts [11]. The original items were developed for engineering experts (e.g., I think I will achieve my engineering goal in the future) so the items were revised to eliminate the content of engineering. The revised items asked to indicate how much they think they can achieve the goal. Specific examples of items were "I think I will achieve my goal in the future." and "I believe I have ability to achieve my goal." The measurement showed acceptable internal consistency (Cronbach $\alpha, 0.85$ ).

\section{3) Social value of goal}

Participants responded to how much they were concerned with the society and others' benefits beyond their own advantages when setting and pursuing their goals. The items were adopted from the Social concern scale that was developed by Shin et al., 2014 [12]. Specific examples of items were "I consider it important to be ethical." and "I have a goal to be a productive member of the society." The measurement showed acceptable internal consistency (Cronbach $\alpha, 0.83$ ).

\section{Data analysis}

\section{1) Goal contents categorization}

In the first phase of the data driven analysis, students' descriptions of their life goal were identified. Each life goal was categorized into goal contents classification based on the descriptions of goals and the reasons or critical events related in the setting the goal [13]. Three independent researchers majoring in educational psychology conducted coding and their categories were compared and negotiated until valid categories were found. The average interrater reliability (Cohen's $\kappa$ ) was 0.92 .

As a result of goal contents analyses by major, goal contents are classified as happiness, social concern, self-growth, fame, wealth, well-being, health, social relations, and etc. The following are examples in each category. In the case of happiness, "living a happy life," "leading a cheerful life," "keep smiling," "living a fun life" were included. Social concern of goal included example such as "becoming a contributive intellectual," "human welfare improvement," and "doing volunteer work for others." Self-growth included "living a developing life," "never wasting a day," "self-formation and self- 
realization," "becoming better than who I was yesterday." Fame goal included "gaining recognition," "being acknowledged like a unique brand image," "living a respectable life," "achieving fame and prestige." In the wealth section, people included material value-oriented lists such as "coining money," "becoming rich," "succeeding in business," and "financially holding a higher position over others." Well-being example was "retaining the peaceful state of mind," and health example was "good health and long life." Social relation goal included the enhancement of personal connections, such as "getting a position at military governmental organizations." Lastly, "etc" was made for examples outside specific categories, such as simply "becoming a doctor" or "human."

\section{2) Statistical analysis}

Statistical analysis was operated on the SPSS version 18.0 (SPSS Inc., Chicago, USA), through methods of descriptive statistics, correlation, Mann-Whitney U test and hierarchical linear regression. In the case of regression, age and gender were processed in the first equation, and the three goal characteristics in the second equation to predict major satisfaction. All the analyses were conducted by the standard of two-tailed and significance level of $5 \%$.

\section{Results}

Percentages of each goal contents were presented in Table 1. Goal contents are composed of eight categories, in which happiness includes the greatest number in both medical and business students, 27.8\% in medical students and 33\% in business students. Medical students had a higher tendency of $26 \%$ students towards social concern of goal, whereas the corresponding value was $6 \%$ in business students. Furthermore, business students had a higher tendency towards wealth goal (24.0\%), in contrast to $7 \%$ in medical school students. Both group shared a similar tendency towards other contents of goals such as self-growth, fame, well-being, health, and social affiliation.

Table 2 shows descriptive statistics of goal characteristics and major satisfaction. A Mann-Whitney U test confirmed that goal attainability $(U=3,596.50, p<0.01)$, social value of goal $(U=2,198.00, p<0.001)$, and major satisfac tion $(U=2,962.50, p<0.001)$ were higher in medical students than business students. A mean difference was the highest in social value of goal. There were positive correlations between goal characteristics and major satisfaction ranging from 0.23 to 0.45 (Table 2).

Table 1. Descriptions of the Goal Contents

\begin{tabular}{lccc}
\hline \multicolumn{1}{c}{ Category } & Medical $(\mathrm{n}=97)$ & Business $(\mathrm{n}=96)$ & Total $(\mathrm{N}=193)$ \\
\hline Happiness & $27(27.8)$ & $32(33.3)$ & $59(31.1)$ \\
Self-growth & $27(27.8)$ & $24(25.0)$ & $51(26.8)$ \\
Social concern & $25(25.8)$ & $6(6.3)$ & $31(16.3)$ \\
Fame & $7(7.2)$ & $8(8.3)$ & $15(7.9)$ \\
Wealth & $3(3.1)$ & $23(24.0)$ & $26(13.7)$ \\
Well-being & $1(1.0)$ & $1(1.0)$ & $2(1.1)$ \\
Health & $1(1.0)$ & 0 & $1(0.5)$ \\
Social relations & 0 & $2(2.1)$ & $2(1.1)$ \\
Etc & $3(3.1)$ & 0 & $3(1.6)$ \\
Missing & $3(3.1)$ & 0 & $3(1.5)$ \\
Total & $97(100.0)$ & $96(100.0)$ & $193(100.0)$ \\
\hline
\end{tabular}

Data are presented as number $(\%)$. 
Table 2. Descriptive Statistics And Correlations Of The Goal Characteristics And Major Satisfaction

\begin{tabular}{|c|c|c|c|c|c|c|c|c|c|}
\hline \multirow{2}{*}{ Variable } & \multicolumn{2}{|c|}{ Median } & \multicolumn{2}{|c|}{ 1st-3rd quartile } & \multirow{2}{*}{ U } & \multicolumn{4}{|c|}{ Correlations } \\
\hline & Medical & Business & Medical & Business & & 1 & 2 & 3 & 4 \\
\hline Goal characteristic & & & & & & & & & \\
\hline 1. Goal autonomy & 4.60 & 4.40 & $4.00-5.00$ & $4.00-5.00$ & $4,328.50^{\mathrm{al}}$ & - & $0.65^{* * *}$ & $0.13^{\mathrm{al}}$ & $0.23^{*}$ \\
\hline 2. Goal attainability & 4.20 & 4.00 & $4.00-4.80$ & $3.65-4.60$ & $3,596.50^{* *}$ & $0.65^{* * *}$ & - & $0.32 * *$ & $0.26^{*}$ \\
\hline 3. Social value of goal & 4.20 & 3.40 & $3.80-4.70$ & $2.85-4.00$ & $2,198.00^{* * *}$ & $0.43^{* * *}$ & $0.49^{* * *}$ & - & $0.32^{* *}$ \\
\hline 4. Major satisfaction & 4.00 & 4.00 & $4.00-5.00$ & $3.00-4.00$ & $2,962.50 * * *$ & $0.29 * *$ & $0.45^{* * *}$ & $0.40^{* * *}$ & - \\
\hline
\end{tabular}

Values below diagonal were from medical students, above diagonal were from business students.

${ }^{a}$ Non-significant, ${ }^{*} p<0.05,{ }^{* *} p<0.01,{ }^{* * *} p<0.001$.

\section{Table 3. Effects of Goal Characteristics on Major Satisfaction in Medical Students}

\begin{tabular}{lllcrrrr}
\hline & & $\mathrm{R}^{2}$ & $\Delta \mathrm{R}^{2}$ & \multicolumn{1}{c}{$\beta$} & $\mathrm{B}$ & $\mathrm{SE}$ & $\mathrm{t}$ \\
\hline $1 \quad$ Gender & $0.02^{\mathrm{al}}$ & $0.00^{\mathrm{al}}$ & -0.01 & -0.02 & 0.18 & $0.13^{\mathrm{al}}$ \\
& Age & & & -0.04 & -0.01 & 0.03 & $0.36^{\mathrm{al}}$ \\
Gender & $0.21^{* * *}$ & $0.21^{* * *}$ & 0.06 & 0.13 & 0.16 & $0.82^{\mathrm{al}}$ \\
& Age & & -0.02 & -0.01 & 0.03 & $0.20^{\mathrm{al}}$ \\
& Goal autonomy & & & -0.07 & -0.10 & 0.18 & $0.54^{\mathrm{al}}$ \\
& Goal attainability & & & 0.39 & 0.55 & 0.18 & $3.06^{* *}$ \\
& Social value of goal & & & 0.24 & 0.30 & 0.13 & $2.27^{*}$ \\
\hline
\end{tabular}

B: Standardized coefficient, B: Unstandardized coefficient, SE: Standardized error.

${ }^{a)}$ Non-significant, ${ }^{*} p<0.05,{ }^{* *} p<0.01,{ }^{* * *} p<0.001$.

Table 4. Effects of Goal Characteristics on Major Satisfaction in Business Students

\begin{tabular}{|c|c|c|c|c|c|c|c|}
\hline & & $\mathrm{R}^{2}$ & $\Delta \mathrm{R}^{2}$ & $\beta$ & B & SE & $\mathrm{t}$ \\
\hline \multirow[t]{2}{*}{1} & Gender & $0.01^{\text {al }}$ & $0.01^{\mathrm{al}}$ & -0.03 & -0.05 & 0.19 & $0.25^{\mathrm{al}}$ \\
\hline & Age & & & 0.10 & 0.04 & 0.04 & $0.84^{\mathrm{al}}$ \\
\hline \multirow[t]{5}{*}{2} & Gender & $0.10^{* * *}$ & $0.10 * * *$ & -0.02 & -0.03 & 0.18 & $0.18^{\mathrm{al}}$ \\
\hline & Age & & & 0.10 & 0.02 & 0.04 & $0.48^{\mathrm{al}}$ \\
\hline & Goal autonomy & & & 0.15 & 0.18 & 0.16 & $1.12^{\mathrm{al}}$ \\
\hline & Goal attainability & & & 0.08 & 0.10 & 0.18 & $0.55^{\mathrm{al}}$ \\
\hline & Social value of goal & & & 0.27 & 0.31 & 0.12 & $2.58^{*}$ \\
\hline
\end{tabular}

B: Standardized coefficient, B: Unstandardized coefficient, SE: Standardized error.

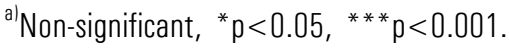

Results from hierarchical regression analyses of medical students are presented in Table 3. The coefficients of goal attainability $(\beta=0.39, \mathrm{t}=3.06, \mathrm{p}<0.01)$ and social value of goal $(\beta=0.24, t=2.27, p<0.05)$ were significant for predicting major satisfaction. The higher a medical student's perceived goal attainability and social value of goal was, the more he or she was satisfied in the major.
Results from hierarchical regression analyses of business students are presented in Table 4. The coefficient of social value of goal $(\beta=0.27, t=2.58, p<0.001)$ was only significant for predicting major satisfaction. The higher a medical student's social value of goal was, the more he or she was satisfied in the major. 


\section{Discussion}

Goal contents that differed by major appeared to be social concerns of goal and wealth. The percentage of social concerns of goal was higher in medical students. On the other hand, the percentage of wealth pursuit was higher in business students. This result is a positive answer to the society's concern about whether medical students truly value human-centered treatment rather than the prestigious social authority or wealth that the profession generally brings about. Wealth-oriented medical students showed a low percentage and most of the goal contents were related to intrinsic goals such as social concerns and self-growth. In contrast, business students showed a tendency towards wealth-oriented goals. This result equals with former research in which the major characteristics of business led to wealth pursuit [9]. Medical students had higher satisfaction in more goal characteristics (i.e., goal attainability, social value of goal) and their major, which is a signifier that explains the conclusive information of medical students' higher proportion of intrinsic social concerns of goal [14]. The superiority of goal characteristics over business students also stand for the higher proportion of intrinsic goals of medical students.

Medical students showed higher major satisfaction of score 4 or higher on average. Considering the concerns on medical students' high stress level and its convertsion to low major satisfaction [15], a result like this is encouraging. It signifies the presence of psychological basis prepared for medical students to help retain a high level of major satisfaction. Major satisfaction plays an important role in medical science development or a preprofessional's progress, owing to the fact that it may have a positive effect on one's future course after graduation or thinking [16]. Therefore, an adequate in- stitutional support may maximize the promotion of medical experts.

Examination upon the relationship between goal characteristics and major satisfaction has revealed that goal attainability and social values may significantly predict major satisfaction of medical students. This result indicates that in order to heighten medical students' major satisfaction, a plan that grasps the goal contents and elevate goal attainability is effective in enhancing major satisfaction [17]. In addition, it signifies that during the goal-setting phase, educational support should be provided for medical students' social value cultivation. Importance of social concern value or sense of community has increased along with the need to promote a professional who may contribute to the society [18]. The results of this study confirmed the fact that university students' positivity of social value pursuit in increasing an individual's major satisfaction. Therefore, there is a need for educational institutions to inform individuals of the relationship between major knowledge and societal development, and to constitute programs of which medical students are educated of the contribution of medical science on societal development such as national economic growth and welfare promotion. Through these attempts, students should be provided of an environment in which they may be allowed to think of social values and pursue social concerns of goal.

There are several limitations of this study and suggestions for future research. Firstly, the recruitment group's goal contents were comprehended through surveys not interviews, a measure that carries limitation in in-depth study. In this study, questions on the reasons for setting certain goals were included for understanding the goal thoroughly, but still in-depth understanding of the goal contents is not sufficient. This research may act as a foundational research for future study of qualitative research methods such as interviewing. Second, there 
could be other important goal characteristics that provide a meaningful explanation for major satisfaction. For example, goal commitment may also be linked closely to major satisfaction. This research has examined three goal characteristics under the theoretical framework of GCT, but it is necessary future research should consider a diversity of goal characteristics. Third, this study only include two disciplines of medical and business. Since insufficient level of research has been done for comparing goals in these two fields, this study works as foundation for revealing goal difference between the fields. However, further studies should be performed to compare the goal of majors that are related to medicine (e.g., pharmacy, nursing) and not related to medicine (e.g., art, engineering). It would provide a greater comprehensive picture to suit the dynamics of the modern education. Lastly, multiple psychological variables related to choosing a major, goal contents and goal characteristics were not included. Since many factors such as family background, admission grade, and individual aptitude affect the choice on one's major and goal, future study should be engaging in a wider variety of psychological variables and their relationship with goal contents and goal characteristics.

Acknowledgements: None.

Funding: This work was supported by the National Research Foundation of Korea Grant funded by the Korean Government (NRF-2013S1A3A2055007).

Conflicts of interest: None.

\section{References}

1. Locke EA, Latham GP. Building a practically useful theory of goal setting and task motivation: a 35-year odyssey. Am Psychol 2002; 57: 705-717.

2. Klein HJ, Wesson MJ, Hollenbeck JR, Alge BJ. Goal commitment and the goal-setting process: conceptual clarification and empirical synthesis. J Appl Psychol 1999; 84: 885-896.

3. Locke EA, Latham GP. A theory of goal setting \& task performance. Englewood Cliffs, USA: Prentice-Hall; 1990.

4. Kim S, Hur Y, Park JH. The correlation between achievement goals, learning strategies, and motivation in medical students. Korean J Med Educ 2014; 26: 19-24.

5. Jeon S, Lee YM, Park SH. The effects of medical students' achievement goal orientations on affective attitudes towards anatomy learning. Korean J Med Educ 2008; 20: 189-198.

6. Ryan RM, Deci EL. Self-determination theory and the facilitation of intrinsic motivation, social development, and well-being. Am Psychol 2000; 55: 68-78.

7. Kasser T, Ryan RM. Further examining the American dream: differential correlates of intrinsic and extrinsic goals. Pers Soc Psychol Bull 1996; 22: 280-287.

8. Vansteenkiste M, Niemiec CP, Soenens B. The development of the five mini-theories of self-determination theory: an historical overview, emerging trends, and future directions. In: Urdan TC, Karabenick SA, eds. The decade ahead: theoretical perspectives on motivation and achievement. Bingley, UK: Emerald Group Publishing; 2010. p 105-165. (Advances in motivation and achievement; vol. 16, part A).

9. Kasser T, Ahuvia A. Materialistic values and well-being in business students. Eur J Soc Psychol 2002; 32: 137-146.

10. Vansteenkiste M, Duriez B, Simons J, Soenens B. Materialistic values and well-being among business students: further evidence of their detrimental effect. J Appl Soc Psychol 2006; 36: 2892-2908.

11. Shin JH, Park SW, Lee YK, Shin SI, Rhee SH. Development of a goal questionnaire for engineering 
experts. Korean J Educ Psychol 2012; 26: 353-376.

12. Shin JH, Jin SJ, Rhee SH, Park SW, Kim YE, Kim SH. A study on the differences in goal contents and goal-seeking processes according to expertise levels of professional engineers and artists. Korean J Educ Psychol 2014; 28: 455-476.

13. Ryan RM, Sheldon KM, Kasser T, Deci EL. All goals are not created equal: an organismic perspective on the nature of goals and their regulation. In: Gollwitzer PM, Bargh JA, eds. The psychology of action: linking cognition and motivation to behavior. New York, USA: Guilford Press; 1996. p 7-26.

14. Vansteenkiste M, Lens W, Deci EL. Intrinsic versus extrinsic goal contents in self-determination theory: another look at the quality of academic motivation. Educ
Psychol 2006; 41: 19-31.

15. Jun JY, Kim SA, Moon DS, Kang DW, Park WS. An analysis of influencing factors on the medical students' stress. Kwandong Med J 2000; 4: 127-135.

16. Jang SC. An analysis of type of university students' career decision. Korean J Couns Psychol 2004; 16: 533551.

17. Wigfield A, Eccles JS. Expectancy-value theory of achievement motivation. Contemp Educ Psychol 2000; 25: $68-81$.

18. Yeager DS, Henderson MD, Paunesku D, Walton GM, D'Mello S, Spitzer BJ, Duckworth AL. Boring but important: a self-transcendent purpose for learning fosters academic self-regulation. J Pers Soc Psychol 2014; 107: 559-580. 